\title{
A ação sindical e a precarização do trabalho: o caso dos Shoppings Centers
}

\author{
Isabella Bino da Silva \\ Recebido em maio de 2019 \\ Aceito em outubro de 2019
}

\section{RESUMO}

Este artigo trata-se de uma síntese do trabalho de conclusão de curso que analisa a ação sindical do Sindicato dos Trabalhadores em Empresas Estabelecidas em Shopping Centers de Curitiba (SINDSHOPPING) e sua relação com os trabalhadores. Para isso traçamos um breve histórico sobre a reestruturação produtiva do trabalho; o desenvolvimento sindical e sobre o aumento do trabalho no comércio a partir dos anos 1990. É analisado o baixo histórico de reivindicações e ações dos sindicatos dos comerciários, bem como, as vivências e contradições dos trabalhadores do shopping para lidar com a extensa jornada de trabalho, os baixos salários e a fragmentação. Resultando em trabalhadores altamente precarizados e flexibilizados, além de reféns dos patrões que possuem grande poder discricionário. O estudo revela a fragilidade da organização sindical nos locais de trabalho, o distanciamento da base e por outro lado, também o desinteresse dos trabalhadores pelo sindicato, em parte devido a suas relações individuais com o patronato.

Palavras-chave: Flexibilização; Precarização; Shopping; Sindicato; Trabalhadores.

\begin{abstract}
This paper consists of a synthesis of the course conclusion paper that analyzes the unionist actions of the Workers' Union in Curitiba Shopping Centers (Sindicato dos Trabalhadores em Empresas Estabelecidas em Shopping Centers de Curitiba SINDSHOPPING), and its relationship with the workers. We will draw a brief history of the productive restructuring of work; union development and the increase in trade work since the 1990s. Next, we'll analyze the poor history of claims and lawsuits of the trade unions, as well as the experiences and contradictions of the mall workers in dealing with extensive working hours, low wages and fragmentation. Resulting in highly devalued and strained workers, hostages to discretionary employers. The study reveals the fragility of union organization in the workplace, the distance from the base and the other hand, also the workers' lack of interest, partly due to their individual relationships with the worker employer.
\end{abstract}

Keywords: Flexibility; Precariousness; Shopping; Labor union; Workers.

Este artigo traz as principais considerações resultantes da análise levantada na pesquisa monográfica apresentada em 2018 como requisito para obtenção do diploma de licenciatura em Ciências Sociais pela Universidade Federal do Paraná (UFPR). O

\footnotetext{
1 Licenciada em Ciências Sociais pela Universidade Federal do Paraná. Email: isabellabino.silva@gmail.com
} 
problema da pesquisa (SILVA, 2018) ${ }^{2}$ foi levantado mediante a experiência pessoal de trabalhar dentro do shopping, atentei para grande quantidade de trabalhadores dentro de uma estrutura comercial, que tinham peculiaridades em relação a outros trabalhadores de comércio, como o de rua, por exemplo.

Durante cinco anos trabalhei em uma loja de shopping, pela necessidade de ter um emprego que permitisse uma remuneração suficiente para pagar o aluguel, os estudos, alimentação e ao mesmo tempo, que eu pudesse trabalhar no turno da tarde e da noite para poder estudar pela manhã. Desde o início do trabalho notei que haviam poucos diálogos sobre o sindicato, muitas vezes nem mencionado ou conhecido pelos colegas de profissão. Na minha experiência como vendedora percebi a precarização deste trabalho, com um profundo discurso meritocrático com forte cultura da empresa, onde os trabalhadores "vestem a camisa" da empresa e aliado a isso grande proximidade com os patrões que reafirmam essa cultura.

Uma estrutura comercial que fica aberta em média $78 \mathrm{~h}$ semanais, incluindo domingos e feriados, que acolhe milhares de trabalhadores (apenas no shopping Palladium no bairro Portão em Curitiba, existem aproximadamente 4500 funcionários nas lojas), não apresenta uma entidade forte para proteger esses trabalhadores, deixando-os a mercê dos patrões, que regulam e inserem uma ideologia individualista e competitiva.

Em uma conjuntura de falta de perspectiva política, falta de emprego e vindo de uma categoria que depende do volume de vendas para melhorar o salário. Procuro identificar quais ações o Sindshopping construiu com os trabalhadores nos últimos anos e qual a relação entre sindicato e trabalhadores? Por último, quais as contradições que encontramos entre a ação sindical fraca e a alta fragmentação dos trabalhadores que dificulta uma ação coletiva.

O trabalho de conclusão de curso foi realizado com base nesses questionamentos e análises. Foram realizadas entrevistas semi-estruturadas, todas realizadas pela autora, com vinte e cinco trabalhadores divididos em quatro shoppings de Curitiba (Shopping Palladium, Shopping Cidade, Shopping Estação e Polloshop Alto

${ }^{2}$ SILVA, I. A ação sindical e a precarização do trabalho: o caso dos Shoppings Centers. Monografia (graduação em Ciências Sociais) - Universidade Federal do Paraná. Setor de Ciências Humanas, p. 94. 2018. 
da XV), durante o período de março a junho de 2018. A escolha dos shoppings foi baseada pela localização, sendo o shopping Palladium e Cidade localizados em bairros mais distantes do centro e shopping Estação e Polloshop mais próximos do centro de Curitiba. Também foi realizada uma entrevista com a presidente do Sindshopping (Sindicato dos Trabalhadores em Empresas Estabelecidas em Shopping Centers de Curitiba) e uma entrevista com o representante político do SINDICOM (Sindicato dos Empregados do Comércio de Curitiba), ambos em março de 2018.

Para poder compreender melhor a ação sindical dessa categoria, realizamos um resgate histórico sobre a reestruturação produtiva ocorrida nos anos 1990. Analisando a abertura comercial proposta pelo presidente Fernando Henrique Cardoso que aumentou a flexibilização do trabalho, intensificando as jornadas e aumentando a concorrência por emprego. Gerando um aumento no número de empregos no comércio.

\section{A mudança no mundo do trabalho: flexibilização e precarização}

Segundo Rodrigues (2009) a Constituição Federal de 1937, considerou os sindicatos como órgãos do Estado, ou seja, como uma entidade corporativista. O autor explica em sua tese, que o corporativismo é uma prática onde o Estado regula as associações para manter a "harmonia" entre as partes. Esse intervencionismo estatal, capitaneado por Getúlio Vargas, fez com que os sindicatos diminuíssem as práticas mais combativas e se caracterizassem com cunho mais assistencialista, como mostra Lima:

Tais sindicatos caracterizavam-se como entidades de cunho assistencialista, com procedimentos que levaram a um esvaziamento dos sindicatos que perdiam legitimidade na representação. Esvaziamento que o governo tentou contornar instituindo inovações nas funções dos sindicatos, a fim de torná-los atrativos para a massa de trabalhadores. Criou cooperativas de crédito e consumo, de escolas, assistência médica, entre outros serviços para os legalmente sindicalizados. (LIMA, 2006. p. 36).

É importante entendermos como os sindicatos têm sido enfraquecidos por políticas externas e regulamentos que dificultam uma tomada de decisão e autonomia. 
Desde o princípio da organização sindical até o chamado "novo sindicalismo" (Cardoso, 1999), que revolucionou o mecanismo de luta sindical diante da globalização, nascido durante as greves de 1978, no ABC paulista.

A década de 1990 trouxe o plano de abertura comercial e privatizações, esse cenário transformou o mercado de trabalho em um contexto altamente precarizado e necessitando de maior proteção. Também trouxe alta taxa de desemprego e o discurso da competitividade, favorecendo a implantação da reestruturação e incorporação de novos padrões produtivos nas empresas. Assim, o sindicalismo nacional passou por uma reorganização de práticas, culminando na diminuição de sua presença no cenário nacional. Segundo Alves (2009),

\footnotetext{
Desde o início da década de 1990, os grandes empresários privados, acompanhando a ofensiva neoliberal no plano da gestão macroeconômica e reorganização patrimonial do Estado brasileiro (com a privatização das empresas estatais e abertura das Reformas do Estado: Reforma da Previdência, Reforma Administrativa, Reforma Tributária, etc., agenda política que percorria a era neoliberal), promovem uma importante ofensiva nas negociações coletivas de trabalho que atinge o metabolismo social da luta sindical classista. A nova postura do grande capital é descentralizar o processo de negociação e flexibilizar os conteúdos dos acordos e convenções coletivas de trabalho. (CAPPA,2000, apud ALVES, 2009, p. 190, 191).
}

No cenário empregado na década de 90 a taxa de desemprego na indústria diminuiu, porém aumentaram consideravelmente os empregos no setor do comércio (NERI, M., CAMARGO, J. M., REIS, M. C, 200o). Com o aumento do emprego no setor do comércio e o sindicato dos comerciários enfraquecido, analisa-se a existência de uma categoria com fraca defesa e atitude combativa, tornando-se um setor altamente precarizado. Patrícia Trópia (2000) mostra em sua pesquisa sobre a posição de retaguarda e conservadorismo do sindicato dos comerciários, que mesmo com a grande movimentação grevista observada na década de 80 até início dos anos 90, alguns setores continuavam à margem do movimento sindical.

Historicamente temos um setor com falha de representação sindical na área comercial, ao mesmo tempo em que grande parte dos trabalhadores tem uma tendência antissindical: são jovens, com baixa escolaridade, alta fragmentação (poucos funcionários em cada empresa e grande quantidade de lojas) e alta rotatividade, pois os 
trabalhadores costumam trocar de loja constantemente, tendendo a pouca movimentação da classe. Patrícia Trópia (2000) mostra que essa situação de trabalho se apresenta como um lugar de conflito entre comerciários e de reprodução da ideologia pequeno-burguesa, isto é, marcado pelo discurso meritocrático e com tendências antissindicais (TRÓPIA, 200o).

O shopping é totalmente pensado para incentivar a visitação, abrangendo setores como a segurança, controle climático, conforto e praticidade, seguindo as regras do mercado. Um resultado tecnológico e comercial de uma sociedade capitalista e a expressão cultural das suas práticas sociais, os shoppings são projetados para dar segurança e conforto aos frequentadores, sendo uma estrutura que abrange todos os setores necessários: loja de roupas, sapatos, bolsas, farmácia, conveniência, eletrônicos, serviços, bancos, ou seja, uma recriação da cidade limpa, protegida e organizada. Assim:

\footnotetext{
O mundo (re) construído dentro de um Shopping Center representa uma realidade socialmente compartilhada, onde a interação dos agentes faz surgir um instrumento urbano único, salvador e irreal. Esse "mundo irreal" obtém vantagem competitiva sobre o tradicional comércio de rua à medida que oferece diversos valores agregados ao consumo dos produtos e dos serviços no seu espaço interior, como shows, sorteios, segurança, espaços climatizados, etc. Eles, os Shoppings, revelam a sua experiência do "novo" através da sua "modernidade", sobrepondo-se ao "velho" das antigas experiências urbanas. (LENGER e CAVEDON, apud TOMAZINI, T.; MACÊDO, K. B. 2010, p. 18).
}

\section{O Shopping Center e a representação sindical}

A representação sindical dentro do shopping mostra-se necessária visto que há uma alta taxa de irregularidades, entre eles: carga horária dependente do fluxo de clientes (podendo ultrapassar 12h diárias), atraso no pagamento, falta de pagamento de horas extras, múltiplas funções, organização de vitrine, controle de estoque, limpeza e caixa, como analisaremos nos próximos tópicos, além da extensa jornada de trabalho (trabalho em escala 6xı, incluindo domingos e feriados). Diante disso, vemos a necessidade de um sindicato forte que consiga representar e defender os direitos dessa categoria, para melhorar as condições de trabalho, mas encontramos um sindicato fraco, que parece pouco dialogar com sua base. 
Para análise contamos com uma entrevista semi-estruturada com a Presidente do SINDSHOPPING 3 , e com o assessor político do SINDICOM. Nessa última entrevista foi indagado o motivo do Sindicato dos Comerciários não representar os trabalhadores do shopping, a hipótese era de que essa divisão de representação era uma das causa na precarização do trabalho no shopping. A entrevista com o SINDICOM foi essencial na análise do trabalho, pois possibilitou entendimento da quebra de representação sindical, entre trabalhadores do comércio em geral (rua, galerias, etc.) e dos trabalhadores de shoppings centers. Segundo o entrevistado do SINDICOM, o sindicato dos comerciários sempre representou os trabalhadores de shoppings, porém a briga pela abertura aos domingos e feriados causou a quebra de representação. Segundo fala do entrevistado do SINDICOM:

Quando foi iniciada a construção do Shopping Mueller, na década de 1980, o discurso era do progresso. Uma instituição comerciária que geraria empregos para estudantes e pessoas de mais idade, mas isso estava bonito só no papel. Assim que o Shopping Mueller abriu, o regime que se encontrava era de análoga à escravidão, trabalhadores comerciários que trabalhavam 10 até 12 horas diretas. (Entrevista com assessor político sindical, em 10 mar 2018).

Trata-se de uma divisão na base que provoca efeitos na capacidade de luta da categoria, visto que o princípio da solidariedade e coletividade é elemento central para a ação coletiva. A rachadura na base sindical, a partir da criação de um sindicato que regulamenta os trabalhadores de shopping especificamente, ao que parece, foi um dos fatores que possibilitou a grande flexibilidade nas jornadas de trabalho.

Pela entrevista com o SINDICOM foi levantada a hipótese de que o SINDSHOPPING foi criado por donos de lojas, que compreenderam a necessidade de abrir aos domingos e feriados e resolveram liderar o sindicato, isso nos ajuda a compreender o motivo deste sindicato ter um histórico tão afastado da base e com tendências conservadoras e assistencialistas. É um sindicato que ainda não possui código sindical ${ }^{4}$ e justifica por isso o afastamento da categoria.

\footnotetext{
3 SINDSHOPPING. Página Inicial. Disponível em: http://sindshopping.com.br/ Acesso em $10 / 10 / 2018$.

4 O Código Sindical é uma sequência numérica que permite as entidades sindicais a emissão das guias de recolhimento e o recebimento dos valores pagos a título de Contribuição Sindical pelas
} 
Nas entrevistas, percebe-se que, ao mesmo tempo em que há um sindicato enfraquecido e historicamente longe de sua categoria, temos, de outro lado, trabalhadores que não se aproximam do sindicato, pois concebem suas relações de trabalho como relações pessoais e as desigualdades de resultados como mérito pessoal, gerando uma disputa interna entre os vendedores. Essa categoria, portanto, submetese a ideologia da meritocracia e revela a hierarquia como um fator natural, resultado do esforço individual. O trabalhador percebe-se como responsável pelo andamento da empresa, quase como um "sócio", gerando um pensamento individualista e meritocrático.

Pela entrevista realizada com a presidente do SINDSHOPPING, o motivo do afastamento do sindicato é justificado pela falta de apoio dos próprios trabalhadores, informando que poucas vezes o sindicato é procurado e somente possui movimento no momento da entrega da carta de oposição ao desconto da contribuição sindical. Porém, o sindicato mostrou-se pouco disposto a estreitar os laços com a base, sempre se justificando pela falta de dinheiro ou pela falta de apoio dos trabalhadores, isso deixa o sindicato com uma força política fraca e deixa os trabalhadores ao arbítrio do patrão. Esse fato que enfraquece a ação coletiva em busca da melhoria das condições de trabalho, juntamente com a relação próxima entre patrões e empregados, faz com que a ação sindical, que já é reduzida, mantenha-se em um campo político de difícil atuação.

Muitas vezes, esses trabalhadores absorvem a cultura da empresa em que trabalham, cultura essa definida por Aktouf (apud Bridi, 2008), como as normas aprendidas e socializadas por membros da organização que molda o pensar e o agir do trabalhador. Essa ideologia é uma forma de domínio do patrão com o objetivo de conseguir maior lucro, forjando uma identidade do trabalhador com a empresa. (BRIDI, 2008). Portanto, uma ação mais estrutural visando atingir um bem comum, alterando as condições gerais de trabalho, torna-se quase impossível.

A repressão à ação coletiva, o poder quase ilimitado dos empregadores para demitir e contratar, a ampla descentralização das negociações, a abrangência

empresas e empregados. Atualmente o SindShopping já possui o código sindical, informado na página inicial do site. 
limitada e hierarquizada das instituições do trabalho, os baixos rendimentos, foram responsáveis por um padrão de desenvolvimento subordinado e com fraco poder distributivo. No interior das empresas, por seu turno, com os trabalhadores sem representação nos locais de trabalho, predominavam as formas predatórias, pessoais e autoritárias de gestão (COSTA, M; MOREL, C; FERREIRA, M. \& BRANDÃO, R. 2006, p.133).

\section{Condições de trabalho no shopping}

No shopping temos um perfil de trabalhadores tradicionalmente marcados pela baixa qualificação e pelos baixos salários, assim como pela alta rotatividade, utilizados pelos empresários para baratear e disciplinar os trabalhadores. Uma pesquisa feita pelo DIEESE (200o) mostrou que cerca de $40 \%$ da força de trabalho no comércio permanece empregada em um período inferior a um ano, assim como crescem anualmente os regimes de contratos temporários que também barateiam os custos do trabalho, diminuindo assim, os contratos com carteira assinada e por tempo indeterminado. Esses fatos se igualam também no caso dos trabalhadores de shopping. Os depoimentos dos trabalhadores entrevistados comprovam que, em sua maioria, eles permanecem na área do comércio por alguns anos, porém mudam constantemente de empresa.

O efeito desse tipo de trabalho é o desgaste físico e emocional, consequência da alta carga de trabalho, da constante necessidade de provar um bom desempenho comparado "ao outro", aliado à extensa jornada, incluindo domingos e feriados. Outro fator que identificamos nas entrevistas é a constância de empresas que mantém seus quadros de funcionários enxutos, conforme o relato de uma vendedora:

Há alguns anos a gente trabalhava em quatro na loja, uma pessoa abria, outra chegava no intermediário e duas ficavam até fechar a loja. Era tranquilo, apesar que tinha muita briga por venda, mas ninguém precisava dobrar ${ }^{5}$ ou ficar horas a mais. De um tempo pra cá, o patrão demitiu todo mundo a gente está em duas só, uma que abre e eu fecho. Quando uma folga normalmente a outra dobra, fim de semana também é normal dobrar. Fora que ninguém pode ficar doente né, se não eles acham ruim. Não falam nada, mas a gente sabe que acham ruim. (Vendedora. Entrevista realizada em 25 de abr. 2018).

${ }^{5} \mathrm{O}$ termo dobrar se refere ao costume de entrar no shopping no horário de abertura e sair apenas no fechamento, ou seja, trabalhar durante as $12 \mathrm{~h}$ em que o shopping permanece aberto. 
O quadro 1 mostra o perfil desse trabalhador, no que se refere ao sexo, idade, estado civil e escolarização. QUADRO 1 - PERFIL DOS TRABALHADORES DE ACORDO COM AS
ENTREVISTAS

\begin{tabular}{|c|c|c|c|c|c|}
\hline Entrevistado & Shopping & Sexo & Idade & $\begin{array}{l}\text { Estado } \\
\text { Civil }\end{array}$ & Escolaridade \\
\hline Entrevista 1 & Palladium & $\begin{array}{l}\text { Mascul } \\
\text { ino }\end{array}$ & 20 & Solteiro & $\begin{array}{l}\mathrm{EM}^{6} \\
\text { incompleto }\end{array}$ \\
\hline Entrevista 2 & Palladium & $\begin{array}{l}\text { Mascul } \\
\text { ino }\end{array}$ & 26 & Casado & EM Completo \\
\hline Entrevista 3 & Palladium & $\begin{array}{l}\text { Femini } \\
\text { no }\end{array}$ & 23 & Casada & EM completo \\
\hline Entrevista 4 & Palladium & $\begin{array}{l}\text { Femini } \\
\text { no }\end{array}$ & 22 & Solteira & EM completo \\
\hline Entrevista 5 & Palladium & $\begin{array}{l}\text { Femini } \\
\text { no }\end{array}$ & 25 & Solteira & EM completo \\
\hline Entrevista 6 & Palladium & $\begin{array}{l}\text { Mascul } \\
\text { ino }\end{array}$ & 32 & Solteiro & ES Incompleto \\
\hline Entrevista 7 & Cidade & $\begin{array}{l}\text { Mascul } \\
\text { ino }\end{array}$ & 23 & Solteiro & $\begin{array}{l}\text { EM } \\
\text { incompleto }\end{array}$ \\
\hline Entrevista 8 & Cidade & $\begin{array}{l}\text { Femini } \\
\text { no }\end{array}$ & 20 & Solteira & ES incompleto \\
\hline Entrevista 9 & Cidade & $\begin{array}{l}\text { Mascul } \\
\text { ino }\end{array}$ & 40 & Solteiro & $\begin{array}{l}\text { EM } \\
\text { incompleto }\end{array}$ \\
\hline Entrevista 10 & Cidade & $\begin{array}{l}\text { Mascul } \\
\text { ino }\end{array}$ & 24 & Casado & $\begin{array}{l}\text { EM } \\
\text { incompleto }\end{array}$ \\
\hline Entrevista 11 & Cidade & $\begin{array}{l}\text { Mascul } \\
\text { ino }\end{array}$ & 20 & Casado & EM completo \\
\hline Entrevista 12 & Cidade & $\begin{array}{l}\text { Femini } \\
\text { no }\end{array}$ & 36 & Casada & ES Incompleto \\
\hline Entrevista 13 & Cidade & $\begin{array}{l}\text { Femini } \\
\text { no }\end{array}$ & 19 & Solteira & EM Completo \\
\hline Entrevista 14 & Cidade & $\begin{array}{l}\text { Femini } \\
\text { no }\end{array}$ & 25 & Solteira & ES incompleto \\
\hline Entrevista 15 & Estação & $\begin{array}{l}\text { Femini } \\
\text { no }\end{array}$ & 30 & Casada & $\begin{array}{l}\text { EM } \\
\text { incompleto }\end{array}$ \\
\hline
\end{tabular}

${ }^{6}$ EM: Ensino Médio 


\begin{tabular}{|l|l|l|l|l|l|}
\hline Entrevista 16 & Estação & $\begin{array}{l}\text { Femini } \\
\text { no }\end{array}$ & $\mathbf{2 5}$ & Solteira & $\begin{array}{l}\text { EM } \\
\text { Incompleto }\end{array}$ \\
\hline Entrevista 17 & Estação & $\begin{array}{l}\text { Femini } \\
\text { no }\end{array}$ & $\mathbf{2 0}$ & Solteira & EM completo \\
\hline Entrevista 18 & Estação & $\begin{array}{l}\text { Mascul } \\
\text { ino }\end{array}$ & $\mathbf{2 7}$ & Solteiro & EM completo \\
\hline Entrevista 19 & Estação & $\begin{array}{l}\text { Femini } \\
\text { no }\end{array}$ & $\mathbf{2 5}$ & Solteira & EM completo \\
\hline Entrevista 20 & Estação & $\begin{array}{l}\text { Mascul } \\
\text { ino }\end{array}$ & $\mathbf{2 1}$ & Solteiro & EM completo \\
\hline Entrevista 21 & Mueller & $\begin{array}{l}\text { Mascul } \\
\text { ino }\end{array}$ & 32 & Casado & ES Incompleto \\
\hline Entrevista 22 & Mueller & $\begin{array}{l}\text { Femini } \\
\text { no }\end{array}$ & 18 & Solteira & EM completo \\
\hline Entrevista 23 & Mueller & $\begin{array}{l}\text { Femini } \\
\text { no }\end{array}$ & 35 & Casado & $\begin{array}{l}\text { EM } \\
\text { Incompleto }\end{array}$ \\
\hline Entrevista 24 & Mueller & $\begin{array}{l}\text { Mascul } \\
\text { ino }\end{array}$ & $\mathbf{2 5}$ & $\begin{array}{l}\text { Solteiro } \\
\text { incompleto }\end{array}$ \\
\hline Entrevista 25 & Mueller & $\begin{array}{l}\text { Femini } \\
\text { no }\end{array}$ & $\mathbf{2 0}$ & Solteira & EM completo \\
\hline
\end{tabular}

Fonte: Pesquisa de Campo, 2018. Elaboração: BINO, 2018.

Pela tabela podemos analisar a baixa escolarização, visto que oito dos 25 entrevistados não possuem o ensino médio completo, mesmo tendo como exigência de contratação a escolarização. Muitas lojas, apesar de exigirem o ensino médio completo, acabam por contratar via indicação de amigos ou outros donos de lojas, também por observação de vendedores de outras lojas. Essa forma de contratação via observação é comum dentro do shopping, durante minha experiência como vendedora de shopping, por diversas vezes observei gerentes ou proprietários de lojas "recrutando" trabalhadores de outras lojas por terem o "dom da venda", vendedores que possuem grande facilidade de vender e realizam esse serviço com sucesso. Portanto, vemos que não há muita exigência em relação a escolarização para contratação de um funcionário, mas sim de qualificação de atributos pessoais, como simpatia, capacidade de trabalhar em equipe, boa fala e postura, facilidade de aprendizado e principalmente envolvimento com a empresa. 
Outra característica marcante nesses trabalhadores é o fator de idade, grande parte desses trabalhadores está abaixo dos 35 anos, como mostra a tabela acima. O comércio sempre foi considerado a porta de entrada para o mercado de trabalho, sendo um dos principais setores econômicos para absorver essa população. Uma pesquisa do DIEESE (2009) 7 mostra que em 2008, aproximadamente $25 \%$ do total de empregados desse setor tinham entre 16 e 24 anos. Alguns fatores a serem considerados são a possibilidade de inserção sem precisar de especialização e o não requerimento de experiência anterior, além da baixa remuneração.

Muitos trabalhadores justificaram a procura pelo horário de trabalho, por ser bastante flexível, sendo possível trabalhar e realizar outras atividades como cursos, faculdade, etc. Porém, verificamos que, em geral, esses trabalhadores abandonam seus estudos ou tem grande dificuldade de prosseguir devido a intensa jornada de trabalho, levando a uma baixa qualificação.

Essa análise da qualificação é interessante, pois podemos observar, no próximo quadro, que devido à baixa qualificação desses trabalhadores e a facilidade de passar de loja em loja trabalhando, os trabalhadores entram nesse ramo e permanecem por vários anos. Apesar de existir uma grande rotatividade dentro do shopping, existe uma lógica de ficar "pulando" de loja em loja, gerando pouca estabilidade dentro das empresas, mas com larga experiência em vendas, como mostra no quadro a seguir:

\section{QUADRO 2 - TRAJETÓRIA DOS TRABALHADORES DE ACORDO COM AS ENTREVISTAS}

\begin{tabular}{|l|l|l|l|l|l|l|}
\hline Entrevistado & Shopping & Função & $\begin{array}{l}\text { Tempo } \\
\text { na } \\
\text { empresa }\end{array}$ & $\begin{array}{l}\text { Tempo em } \\
\text { shoppings }\end{array}$ & $\begin{array}{l}\text { Registro } \\
\text { em } \\
\text { carteira }\end{array}$ & $\begin{array}{l}\text { Registrado } \\
\text { em todas } \\
\text { as } \\
\text { empresas }\end{array}$ \\
\hline Entrevista 1 & Palladium & Vendedor & 6 meses & $\mathbf{2}$ anos & Sim & Sim \\
\hline Entrevista 2 & Palladium & Vendedor & 8 anos & 8 anos & Sim & Sim \\
\hline Entrevista 3 & Palladium & Caixa & $\begin{array}{l}1 \text { ano e } \\
\text { meio }\end{array}$ & $\mathbf{2}$ anos & Sim & Não \\
\hline Entrevista 4 & Palladium & Caixa & 7 meses & 3 anos & Sim & Não \\
\hline Entrevista 5 & Palladium & Vendedora & $\mathbf{2}$ meses & 5 anos & Sim & Sim \\
\hline Entrevista 6 & Palladium & Gerente & 5 anos & 5 anos & Sim & Sim \\
\hline
\end{tabular}

7 DIEESE. O jovem comerciário: trabalho e estudo. Ano I, no 3, maio de 2009. Disponível em: http://www.dieese.org.br/analiseped/2009/2009pedjovenscomerciario.pdf acessado em 26/10/2018. 


\begin{tabular}{|c|c|c|c|c|c|c|}
\hline Entrevista 7 & Cidade & Vendedor & 3 anos & 5 anos & Sim & Sim \\
\hline Entrevista 8 & Cidade & Subgerente & 5 meses & 2 anos & Sim & Sim \\
\hline Entrevista 9 & Cidade & Gerente & 4 anos & 8 anos & Sim & Sim \\
\hline Entrevista 10 & Cidade & Caixa & 8 meses & 2 anos & Sim & Não \\
\hline Entrevista 11 & Cidade & Vendedor & 2 anos & 4 anos & Sim & Não \\
\hline Entrevista 12 & Cidade & Vendedora & 5 anos & 5 anos & Sim & Sim \\
\hline Entrevista 13 & Cidade & Vendedora & 2 meses & 1 ano & Não & Não \\
\hline Entrevista 14 & Cidade & Vendedora & 3 anos & 3 anos & Sim & Sim \\
\hline Entrevista 15 & Estação & Vendedora & 3 anos & 10 anos & Sim & Não \\
\hline Entrevista 16 & Estação & Gerente & 4 anos & 5 anos & Sim & Sim \\
\hline Entrevista 17 & Estação & Vendedora & 6 meses & 2 anos & Sim & Sim \\
\hline Entrevista 18 & Estação & Vendedor & 3 anos & 5 anos & Sim & Sim \\
\hline Entrevista 19 & Estação & Vendedora & 1 ano & 3 anos & Sim & Sim \\
\hline Entrevista 20 & Estação & Vendedor & 1 ano & 1 ano & Sim & Sim \\
\hline Entrevista 21 & Mueller & Gerente & 3 anos & 3 anos & Sim & Sim \\
\hline Entrevista 22 & Mueller & Vendedora & 3 meses & 3 meses & Não & Não \\
\hline Entrevista 23 & Mueller & Subgerente & 5 anos & 8 anos & Sim & Sim \\
\hline Entrevista 24 & Mueller & Gerente & 3 anos & 5 anos & Sim & Sim \\
\hline Entrevista 25 & Mueller & Vendedora & 1 ano & 1 ano & Sim & Sim \\
\hline
\end{tabular}

Fonte: Pesquisa de Campo, 2018. Elaboração: BINO, 2018.

Nessa tabela observamos um fator importante que direcionou nossa hipótese: o sindicato tem uma atividade afastada da base, quando vemos que alguns trabalhadores ainda estão contratados sem registro em carteira, mostrando que o shopping não possui supervisão adequada. A falta do registro em carteira desencadeia perda de direitos e de segurança ao trabalhador, como atraso na aposentadoria e recolhimento do Fundo de Garantia (FGTS).

Outra problemática são os contratos, no shopping é comum encontrarmos, principalmente em épocas de finais de ano, os contratos temporários. São possibilidades de contrato em que o empregador contrata um empregado por um período de tempo determinado, normalmente com o discurso de que se neste período o rendimento do trabalho for bom, existe chance de efetivação. Isto faz com que esses trabalhadores se dediquem muito mais do que o necessário para o trabalho com a esperança de uma efetivação, realizando mais horas de trabalho sem o devido pagamento, sem folgas e descansos. Outro fator que chama atenção no shopping é o período de experiência, onde as empresas mantêm por até 90 dias o empregado em 
experiência para verificar a aptidão ao trabalho. Durante esse período é possível que se realize a rescisão contratual dentro do prazo de 90 dias sem que haja nenhum tipo de prejuízo ao empregador ou ao empregado, ambas as partes podem reincidir ao contrato sem o pagamento de multas. Sobre isso uma trabalhadora destacou:

\footnotetext{
Hoje eu estou há um ano aqui, mas trabalhei em duas lojas antes que me dispensaram logo após o contrato de experiência. Me falaram depois que eles (os patrões) sempre fazem isso, eles têm dois funcionários mais antigos fixos e o restante eles ficam trocando, sempre tem gente procurando mesmo. Eles contratam a pessoa, ela fica três meses ali e depois eles dispensam. Aí não pagam a multa, nem o aviso, a gente não pode sacar o FGTS, nada... A gente sai sem nada quase... Sai mais barato pra eles né? (Vendedora. Entrevista realizada em 28 de abr. 2018).
}

Esse fato caracteriza ainda mais a precariedade do trabalho no shopping, demonstrando que não há nenhum tipo de segurança ao trabalhador e gerando alta taxa de rotatividade de funcionários. A alta rotatividade do comércio é, portanto, mais um fator que dificulta a ação sindical aliado também ao baixo número de funcionários por empresas, gerando uma proximidade grande com o patrão.

A maior parte dos entrevistados revelou que apesar de gostarem do seu trabalho, não consideram aquilo como algo permanente e sim provisório. Essa falta de identidade com o trabalho e a individualidade leva esse trabalhador a perceber o trabalho como uma mera fonte de subsistência. A profissão de vendedor, caixa, gerente, não é percebida como uma opção de carreira e sim como algo temporário para a grande maioria. A organização desses trabalhadores dispostos a melhoria das condições de trabalho ou aliados a algum tipo de instituição como o sindicato, mesmo que este fosse propenso a ações mais concretas, é obstaculizada pela percepção de transitoriedade na atividade.

Para garantir os direitos dos trabalhadores temos as Convenções Coletivas de Trabalho (CCT). Essas convenções ou contratos coletivos possuem a finalidade de complementar e regulamentar os contratos individuais, partindo-se do princípio que todo trabalhador, filiado ou não, deve ser representado por um sindicato que negocia as convenções anualmente, para toda categoria de profissionais de uma cidade (CAMARGO, 1996). Dentro do shopping temos a convenção coletiva de trabalho e não 
o acordo coletivo ${ }^{8}$, o primeiro é resultado de um acordo entre entidades sindicais, a dos trabalhadores e a entidade sindical patronal. Enquanto um acordo coletivo é resultado de uma série de normas determinadas pela empresa e pela entidade sindical dos trabalhadores. Não existe hierarquia entre esses acordos.

Essas convenções estipulam condições mínimas de trabalho para os empregados, os contratos coletivos assegurados entre patrões e empregados devem seguir essas normas e possivelmente melhorá-las. O propósito é o de melhoria das condições de trabalho, conferir legitimidade às relações de produção, pacificação de controvérsias e conflitos e por último, geração de normas jurídicas e cláusulas obrigatórias. (DELGADO, 2006). A convenção coletiva desempenha o papel de suprir eventuais ausências nas regulamentações estatais que são específicas de cada categoria, como por exemplo, nesse caso a conferência de caixa. As convenções coletivas abrem espaço também para uma alta flexibilização, grande parte das normas estabelecidas em convenção são abertas a negociação e remetendo a possibilidade do mais forte, no caso a empresa, ser beneficiada em nome da eficiência.

O próximo quadro mostra as condições estabelecidas nas convenções coletivas de trabalho no período entre 2014 e 2018.

\section{QUADRO 3 - CONDIÇÕES ESTABELECIDAS NAS CONVENÇÕES COLETIVAS ENTRE O SINDICATO DOS TRABALHADORES E O SINDICATO PATRONAL. PERÍODO: 2014 A 2018.}

\begin{tabular}{|l|l|}
\hline Temas & Análise das Convenções Coletivas de 2014 a 2018* \\
\hline $\begin{array}{l}\text { Carga } \\
\text { Horária de de } \\
\text { Trabalho }\end{array}$ & $\begin{array}{l}\text { 44h semanais, incluindo domingo e feriados. Nos domingos e feriados a } \\
\text { jornada não pode ultrapassar 6h diárias. (Aberto à negociação caso deseje } \\
\text { estender a jornada domingos e feriados). }\end{array}$ \\
\hline $\begin{array}{l}\text { Pagamento } \\
\text { de Salário }\end{array}$ & $\begin{array}{l}\text { Se pago em dinheiro deverá ocorrer antes do término da jornada entre o7h e } \\
15 \mathrm{~h} \text { de segunda a sexta até o } 5^{\circ} \text { dia útil. Caso não seja pago até esta data } \\
\text { incidira multa de } 5 \% \text { sobre o salário bruto. }\end{array}$ \\
\hline $\begin{array}{l}\text { Adicional } \\
\text { Noturno }\end{array}$ & $\begin{array}{l}\text { Pago } 25 \% \text { de adicional noturno aos funcionários que exercerem suas funções } \\
\text { após às } 22 \mathrm{~h} .\end{array}$ \\
\hline Horas Extras & $\begin{array}{l}\text { De segunda a sábado, primeiras } 40 \mathrm{oh} \text { mensais: } 50 \% \text { de acréscimo sobre as horas } \\
\text { normais. De segunda a sábado, para os excedentes de } 40 h \text { mensais: } 75 \% \text { de }\end{array}$ \\
\hline
\end{tabular}

${ }^{8}$ SINTIGRACE. Saiba a diferença entre acordo coletivo, convenção coletiva e dissídio coletivo de trabalho. o7 de mar de 2013. Disponível em: http://www.sintigrace.org.br/saiba-adiferenca-entre-acordo-coletivo-convencao-coletiva-e-dissidio-coletivo-de-trabalho. Acesso em: 01/11/2018. 


\begin{tabular}{|l|l|}
\hline & $\begin{array}{l}\text { acréscimo. As horas não podem exceder 5oh mensais e terão adicional de 100\% } \\
\text { nos domingos e feriados. Na impossibilidade de descanso intrajornada, a } \\
\text { empresa deverá pagar o intervalo como hora extra. }\end{array}$ \\
\hline $\begin{array}{l}\text { Banco de } \\
\text { Horas }\end{array}$ & $\begin{array}{l}\text { Facultativo às empresas, desde que não exceda o período máximo de 12o dias e } \\
\text { oh diárias. As horas trabalhadas em domingos, feriados e período natalino } \\
\text { não serão computadas como banco de horas. }\end{array}$ \\
\hline $\begin{array}{l}\text { Trabalho em } \\
\text { feriados }\end{array}$ & $\begin{array}{l}\text { Havendo interesse por parte da empresa em aberturas em feriados ou } \\
\text { prorrogação nas vésperas, poderão acordar com o sindicato. Em período } \\
\text { natalino poderão prorrogar o horário de segunda a domingo, no dia 24 de } \\
\text { dezembro até as 18h. }\end{array}$ \\
\hline $\begin{array}{l}\text { Repouso } \\
\text { Semanal }\end{array}$ & $\begin{array}{l}\text { Concedido em qualquer dia da semana. Deverá coincidir, pelo menos uma vez } \\
\text { em no máximo três semanas, com o domingo. }\end{array}$ \\
\hline $\begin{array}{l}\text { Conferência } \\
\text { de Caixa }\end{array}$ & $\begin{array}{l}\text { Será feita na presença do operador responsável, caso não seja possível, não terá } \\
\text { responsabilidade por eventuais erros. }\end{array}$ \\
\hline $\begin{array}{l}\text { Jornada } \\
\text { 12hs/36hs }\end{array}$ & $\begin{array}{l}\text { Implementado jornada 12hs/36hs, exceto para as funções balconista e } \\
\text { vendedor, será acordado de forma direta com o empregador. Neste regime não } \\
\text { será pago hora extra mesmo se forem excedidas às 44h semanais, em face de } \\
\text { compensação. }\end{array}$ \\
\hline
\end{tabular}

Fonte: Convenções Coletivas de Trabalho e termos aditivos de 2014 a 2018. Elaboração: BINO, 2018. *Analisamos ano a ano as convenções, mas como possuem teor igual nos diversos anos analisados, descrevemos no quadro em uma única linha.

Na análise das convenções, destacamos o tempo no trabalho e sua relação com a carga horária regulamentada de $44 \mathrm{~h}$ semanais, incluindo domingos e feriados. Apesar das horas regulamentadas o horário de trabalho é deixado a critério de cada dono de loja, que define entre $6 \mathrm{~h}$ e $9 \mathrm{~h}$ diárias. Dentro dessa lógica, os funcionários que trabalham 6h diárias durante a semana realizam mais horas aos sábados, por ser um dia de maior fluxo de clientes e vendas, assim cumprem às $44 \mathrm{~h}$ semanais. Além das horas regulamentadas em contrato de trabalho, ainda encontramos funcionários que ultrapassam às $44 \mathrm{~h}$ semanais, na lógica da acumulação de vendas. Essas horas acumuladas grande parte das vezes não são pagas nem reembolsadas em banco de horas, uma vez que são feitas "por escolha” do funcionário. Nas entrevistas verificamos que a maioria das lojas não realiza o pagamento de hora extra, porém pareceu haver grande interesse do funcionário em exceder sua jornada, pois assim aumentam suas vendas e consequentemente sua remuneração.

No quesito remuneração encontramos na CCT dois pisos salariais fixados, o normativo fixo, que é a garantia de valor mínimo somado a comissão sobre as vendas e 
o piso comissionista. Este outro tipo é a remuneração do trabalho entregue em substituição ao salário-base, ou seja, o trabalhador receberá pelo serviço prestado e pela comissão, bonificações e extras. Caso o trabalhador não alcance vendas para assegurar o piso para comissionista o empregador deverá pagar-lhe o afixado em convenção para comissionista. A escolha pelo piso a ser seguido é acordado pela empresa que tem autonomia para escolher o piso que quer seguir.

A jornada de trabalho também já foi discutida por outros órgãos como o SINDICOM e o Tribunal Superior do Trabalho (TST). Encontramos uma notícia no site do SINDICOM, que afirma a entrada na justiça, pelo Sindicato dos Comerciários de Curitiba, sobre um suposto ato abusivo pelo empresariado que abriu o shopping durante $32 \mathrm{~h}$ interruptas no ano de 2006. (SINDICOM. Jornada de 32 horas em Shopping Centers vai à Justiça do Trabalho. Folha do Comerciário. Ano XXXIII - ${ }^{\circ} 158$ - março 2016. Disponível em: http://www.sindicom.org/site/noticias/folha0320063.asp. Acesso em: 29/10/2018). A outra notícia é do site do Conjur de abril de 2013, que mostrou a notícia colocada no TST (Tribunal Superior do Trabalho) da obrigatoriedade dos shoppings a fiscalizarem a jornada de trabalho dos empregados dentro das lojas (CONJUR. Shopping é responsável por fiscalizar jornada de lojistas. Conjur, 30 de abr de 2013. Disponível em: https://www.conjur.com.br/2013-abr-30/shopping-responsavelfiscalizar-jornada-empregados-lojistas. Acesso em 29/10/2018). Krein (2013) analisa a extensa jornada de trabalho, fazendo uma relação com a jornada de finais de semana e feriados que prejudicam os trabalhadores, segundo ele:

não há evidências comprovadas de que se eleva o nível de emprego ou de
remuneração. Em segundo lugar, os pequenos comerciantes, fora dos
shoppings, tendem a perder mercado. Quem se beneficia são as grandes
cadeias de lojas, hipermercados, shoppings e o consumidor. Enquanto os
trabalhadores do comércio sofrem com a restrição do uso do seu tempo, os
consumidores veem ampliados os horários que podem realizar suas compras.
Inclusive, é interessante na pesquisa do Provar que os mais entusiastas da
abertura do comércio aos domingos são os que têm melhor renda na
sociedade. (KREIN, 2013, p. 233).

O horário de shopping, por ser de longas jornadas e abrir inclusive domingos e feriados, faz com que os trabalhadores não tenham tempo de estudar ou fazer outras atividades. Krein (2013) mostra que as jornadas aos domingos e feriados não possuem 
quaisquer benefícios comprovados, porém prejudica profundamente os trabalhadores que deixam de ter horas de descanso e socialização. A busca de maior produtividade e competitividade, visto que as lojas de ruas não abrem aos domingos, trata-se de uma flexibilidade com benefícios somente a empresa, permitindo a intensificação nas vendas. A liberação do trabalho aos domingos foi implementada pelo governo

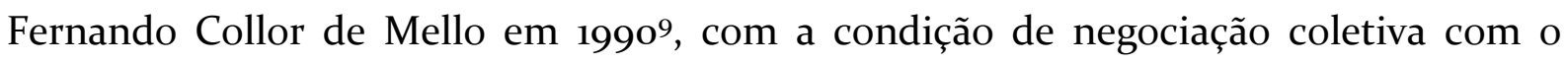
sindicato. Segundo Ângelo e Siqueira (2015), não há dados disponíveis que comprovem a tese de que a abertura aos domingos gere aumento nas vendas e no faturamento, nem dados comprovando o aumento no número de empregos. Para, além disso, temos o ponto de vista cultural e religioso, onde o domingo é reservado para o descanso e lazer. GORZ (2003), afirma que nesse movimento de tempo estendido no trabalho, estão prevalecendo os valores mercantis e individuais, fazendo com que a racionalidade se sobreponha as demais esferas da vida.

Por último temos o ponto de vista dos trabalhadores, nas entrevistas vemos que o trabalho aos domingos possui oposição da maior parte dos trabalhadores, que tem uma visão negativa sobre como ele é regulamentado, pois interfere na vida social e familiar. O trabalho aos domingos é um ponto fundamental na flexibilização desses trabalhadores, que beneficia somente um grupo social no contexto geral, que são os empregadores. Os trabalhadores, por outro lado, perdem seu direito de preservar o convívio familiar e social.

Outro fator que agrega nossa constatação de um sindicato fraco e afastado dos trabalhadores é a quantidade de patrões que não seguem o piso salarial. Oito dos 25 entrevistados disseram que não recebem o piso regulamentado e quatro disseram que não recebem o pagamento até o dia delimitado pela convenção. A baixa coesão entre trabalhadores dificulta a função do sindicato que não se atenta aos problemas enfrentados pela categoria. Por outro lado também temos trabalhadores que não reconhecem o sindicato como entidade de proteção e luta. Essa dificuldade é explicada por diversos fatores: a atividade comerciária ser vista como algo provisório; alta rotatividade entre empresas; desconhecimento das leis trabalhistas e a descrença do sindicato como entidade política. É preciso, portanto, fortalecer o espaço da micro

9 MP n. 1539/97, convertida na Lei n. 10.101/oo. 
regulação e a aproximação entre sindicato e trabalhadores, desenvolvendo também um forte trabalho de base. Tendo um sindicato comprometido em melhorar as condições de trabalho e presentes nos locais de trabalho o que, aparentemente, não ocorre. Isto certamente seria um dos pontos de partida para uma mudança efetiva nas relações de poder nessa cultura autoritária dos lojistas e pouco aberta ao diálogo com os trabalhadores, que caracteriza essas relações de trabalho. (COSTA, 2002).

\section{A reforma trabalhista e o shopping}

Desde o dia 11 de novembro de 2017, novas mudanças nas leis trabalhistas entraram em vigor, ocorrendo profundas alterações nos ordenamentos jurídicos que regulam as relações trabalhistas desde a Consolidação das Leis do Trabalho (CLT) em 1943. A reforma trabalhista, por meio da lei no 13.467 de 13 de julho de 2017 e pela medida provisória 8o8, cria ou revoga mais de cem artigos e parágrafos da CLT. Um dos principais pontos da reforma é a introdução do Artigo 611-A, que afirma sobre os acordos coletivos terem prevalência sobre a lei, dizendo o seguinte:

\footnotetext{
Art. 611-A. A convenção coletiva e o acordo coletivo de trabalho têm prevalência sobre a lei quando, entre outros, dispuserem sobre: I - pacto quanto à jornada de trabalho, observados os limites constitucionais; II - banco de horas anual; III - intervalo intrajornada, respeitado o limite mínimo de trinta minutos para jornadas superiores a seis horas(...) (BRASIL. Lei no 13.467, de 13 de julho de 2017. Altera a Consolidação das Leis do Trabalho (CLT). Diário Oficial da União, Brasília, 2017. Acesso em: 02 out 2018.).
}

Percebe-se que grande parte dos itens propostos, busca flexibilizar a jornada de trabalho e a remuneração e sobre a prevalência da negociação direta ao invés das leis. Isso faz com que o ministério da justiça não possa mais regular sobre o conteúdo dos acordos ou convenções, detendo-se apenas àqueles pontos onde não é passível de negociação como férias, segurança, licenças etc.

Desde sua entrada em vigor, surgiram debates mostrando infinitos problemas e destacando que a lei aprovada implicará em insegurança aos trabalhadores, resultando no maior poder discricionário dos patrões e prejudicando o trabalhador. 
Analisando as condições do trabalho no shopping e sobre o funcionamento do sindicato representante, observamos as dificuldades de relação entre sindicato e base por diversos motivos, sejam eles o discurso meritocrático dos trabalhadores; a proximidade com o patrão; a fragmentação do trabalho e a extensa carga horária. Embora tenhamos observado tais problemas, que implicam em um distanciamento do sindicato da categoria, podemos prever que a reforma trabalhista traz ainda piores condições de trabalho, para uma categoria que já sofre diversas pressões e está afundada em um raciocínio individualista e meritocrático. Não ter nenhum órgão responsável por regulamentar e defender esses trabalhadores é abrir espaço para maior precarização do trabalho.

A reforma ataca diretamente os sindicatos, retirando seu financiamento e suas funções que eram regulamentadas, como obrigação de homologação com a presença do sindicato dos trabalhadores, acesso à assistência jurídica gratuita e a própria contribuição sindical. Indicando, portanto, que a finalidade é acabar com o movimento sindical, quebrando o elo existente entre a entidade sindical e as ações coletivas, facilitando a exploração dos trabalhadores. Segundo Carvalho (2017):

\footnotetext{
A total discricionariedade sobre demissões coletivas permitida pelo Artigo 477-A, aliada à possibilidade da existência de termo de quitação anual de obrigações trabalhistas, tem gerado preocupações, visto que estimularia empregadores a não cumprir a legislação (ou mesmo o acordo), e, posteriormente, pressionarem sindicatos a forçar os trabalhadores a abrirem mão de direitos em troca de emprego. (Carvalho, 2017, p. 88).
}

Também para o sindicato a reforma trabalhista traz inúmeros problemas, principalmente no financiamento, onde retira a obrigação do desconto da contribuição que é a fonte de financiamento sindical. A ideia da reforma é retirar qualquer barreira que os sindicatos possam fazer e facilitar o poder discricionário dos patrões, outro exemplo disso é o ponto que estabelece a demissão coletiva sem a necessidade de intervenção sindical. Segundo Carvalho (2017), até então, a demissão coletiva só poderia ocorrer após negociação entre empresa e sindicato dos trabalhadores, a fim de atenuar a consequência dessas demissões. A partir da reforma é possível ocorrer sem essa intervenção sindical. Apesar de compreender os problemas enfrentados pelo 
sindicato e a relação praticamente inexistente entre sindicato e trabalhadores, é importante que tenhamos ainda uma entidade representativa, seja ela como for, para ser possível uma futura mudança de ação ou maior representatividade. Porém, quando o Estado tenta barrar a própria existência dessa instituição não é possível enxergar uma melhora, mas é possível prevermos maior precarização.

\section{Considerações finais}

O objetivo da pesquisa foi analisar as condições de trabalho no shopping, no que se refere às jornadas, remuneração e contrato dos trabalhadores de shopping de Curitiba, também investigar como se concluem as ações sindicais do SINDSHOPPING, sindicato que representa esses trabalhadores. Ao longo da pesquisa compreendemos que o sindicato em questão não possui um histórico de luta e reivindicação, realizando papel apenas assistencialista e conservador.

A hipótese mais ampla, a partir dessa pesquisa, é a de que, sindicatos fracos, tradicionalmente afastados e muitas vezes dando mais representatividade aos patrões do que aos próprios trabalhadores. Num contexto de ampla competição e reestruturação das condições de trabalho, a jornada de trabalho dessa categoria vem sendo cada vez mais ampliada e a condição de trabalho precarizada. Ao mesmo tempo em que os trabalhadores estão profundamente inseridos em uma cultura da empresa, em um discurso meritocrático e não buscam o sindicato para debater seus direitos.

Concluo, portanto, que encontramos uma contradição nas relações de trabalho. Essas relações são elásticas em sua maioria, não percebendo nenhum limite à jornada de trabalho ou atenção ao trabalho excedente. O patrão afirma seu direito quando procura prolongar a jornada de trabalho e transformar um dia de trabalho em dois. Assim, como previamente apontado por Marx (1975), ocorre uma antinomia, direito contra direito, ambos baseados na lei de troca de mercadorias. A exploração não é nada anormal, é um típico resultado do funcionamento regular do modo de produção capitalista. 


\section{Referências}

ALMEIDA, Marilis Lemos de. Comércio: perfil, reestruturação e tendências. vol.18, n.61, 1997 .

ALVES, Giovanni. Trabalho e reestruturação produtiva no Brasil neoliberal: precarização do trabalho e redundância salarial. Revista Katálysis, vol. 12, núm. 2, julio-diciembre, 2009.

BOITO, Jr. Armando. Reforma e persistência da estrutura sindical, in A. Boito Jr. (Org). O sindicalismo brasileiro nos anos 8o. São Paulo. Paz e Terra. 1991.

BRASIL. Constituição (1988). Constituição da República Federativa do Brasil: promulgada em 5 de outubro de 1988. Organização do texto: Juarez de Oliveira. 4. ed. São Paulo: Saraiva, 1990.

BRASIL. Consolidação das Leis do Trabalho. Decreto-Lei no 5.442, de o1 mai 1943. Disponível em: http://www.planalto.gov.br/ccivil_03/DecretoLei/Del5452compilado.htm. Acesso em: 15 de jun 2018.

BRASIL. Lei no 13.467, de 13 de julho de 2017. Altera a Consolidação das Leis do Trabalho (CLT). Diário Oficial da União, Brasília, 2017. Acesso em: 02 out 2018.

BRIDI, Maria Aparecida. Ação coletiva e comissões de trabalhadores em plantas flexíveis: o espaço da política. Tese de Doutorado. Programa de Pós-Graduação em Sociologia, Setor de Ciências Humanas, Letras e Artes da Universidade Federal do Paraná - UFPR, Curitiba, Paraná, Brasil,20o8.

BRIDI, Maria Aparecida. A Crise da Relação Salarial e o Sindicalismo em Tempos Neoliberais. Revista CRH, Salvador, v. 1, n. 47, p. 293-308, 2006.

CARDOSO, Adalberto Moreira. Sindicatos, trabalhadores e a coqueluche neoliberal: a era Vargas acabou? Rio de Janeiro: Fundação Getúlio Vargas, 1999.

CARVALHO, S. S. Uma visão geral sobre a reforma trabalhista. Boletim Mercado de Trabalho - Conjuntura e Análise no 63. Brasília. IPEA, 2017.

COSTA, Márcia da Silva. Reestruturação produtiva, sindicatos e a flexibilização das relações de trabalho no brasil. Rae-eletrônica. Ed. Fundação Getúlio Vargas. São Paulo, 2002. Disponível em: https://rae.fgv.br/rae-eletronica/vol2-num22003/reestruturacao-produtiva-sindicatos-flexibilizacao-relacoes-trabalho-n. Acesso em: 15 de out 2018.

DAL ROSSO, Sadi - Mais trabalho! A intensificação do labor na sociedade contemporânea. São Paulo: Boitempo, 2008. 
DEDECCA, Claudio Salvatori. Reorganização das relações de trabalho no Brasil. A flexibilidade é a única alternativa? In: CARVALHO NETO, A. M.; CARVALHO, R. (Orgs.). Sindicalismo e negociação coletiva nos anos 9o. Belo Horizonte: IRT/PUCMG, 1998, p.151-18o.

DIEESE. A reestruturação produtiva no comércio. Boletim DIEESE, jan-fev, 2000.

DIEESE. O jovem comerciário: trabalho e estudo. Ano I, no 3, maio de 2009. Disponível em: http://www.dieese.org.br/analiseped/2009/2009pedjovenscomerciario.pdf acessado em $26 / 10 / 2018$.

GORZ, André. Metamorfoses do trabalho: crítica da razão econômica. São Paulo: Annablume, 2003.

MARX, K. O capital. Crítica da economia política. 3.ed. Rio de Janeiro: Civilização brasileira, livro 1, 1975.

MEDEIROS, C. A. Contrato coletivo e mercado de trabalho no Brasil. In: MATTOSO, J. et al. O mundo do trabalho: crise e mudança no final do Século. São Paulo: Scritta, 1994 .

NERI, M., CAMARGO, J. M., REIS, M. C. Mercado de trabalho nos anos 9o: fatos estilizados e interpretações. Rio de Janeiro: IPEA, p. 5, 2000.Acesso em 17/o7/2018.

NORONHA, Eduardo. A explosão das greves na década de 8o. In BOITO, Jr. (org.), O sindicalismo brasileiro nos anos 8o. São Paulo, Paz e Terra, 1991.

OLIVEIRA, Luis Eduardo. Os empregados no Comércio de Juiz de fora e sua luta pelo descanso dominical (1880-1905). Anais do I Colóquio do LAHES. Laboratório de História Econômica e Social da Universidade Federal de Juiz de Fora, 2005.

PARANHOS, Adalberto. O roubo da fala - Origens da ideologia do trabalhismo no Brasil. São Paulo: Boitempo Editorial, 1999.

PINHEIRO, Paulo Sérgio e HALL, Michael M. A classe operária no Brasil: 1889-1930 documentos. São Paulo: Alfa-ômega, 1979.

POCHMANN, M. A Década dos Mitos: O novo modelo econômico e a crise do Trabalho no Brasil. São Paulo: Contexto, 2001.

PORTO, Roberta Guasti. A negociação coletiva de trabalho e a (re) construção das relações de trabalho na sociedade contemporânea. Programa de Pós-Graduação em Direito da Pontifícia Universidade Católica de Minas Gerais, 2012. 
RAMALHO, José Ricardo. Trabalho e sindicato: posições em debate na sociologia hoje. vol.43, n.4, 2000. Disponível em: http://www.scielo.br/scielo.php?pid=Soo1152582000000400006\&script=sci_abstract\&tlng=pt. Acesso em: o1 jul. 2018.

REIN, José Dari. Reforma no sistema de relações de trabalho no Brasil. In: Emprego e desenvolvimento tecnológico. DIEESE/CESIT/UNICAMP, 1999.

RODRIGUES, Leôncio M. Partidos e sindicatos: escritos de sociologia política. Rio de Janeiro: Centro Edelstein de Pesquisas Sociais, 2009.

CONJUR. Shopping é responsável por fiscalizar jornada de lojistas. Conjur, 30 de abr de 2013. Disponível em: https://www.conjur.com.br/2013-abr-30/shoppingresponsavel-fiscalizar-jornada-empregados-lojistas. Acesso em 29/10/2018.

SILVA, I. A ação sindical e a precarização do trabalho: o caso dos Shoppings Centers. Monografia (graduação em Ciências Sociais) - Universidade Federal do Paraná. Setor de Ciências Humanas, p. 94. 2018.

SINDICOM. Jornada de 32 horas em Shopping Centers vai à Justiça do Trabalho. Folha do Comerciário. Ano XXXIII - $\mathrm{n}^{\circ} 158$ - março 2016. Disponível em: http://www.sindicom.org/site/noticias/folhao320063.asp. Acesso em: 29/10/2018.

TOMAZINI, T.; MACÊDO, K. B. As vivências dos trabalhadores de um shopping center em relação ao seu trabalho: uma abordagem psicodinâmica. Revista Gestão Organizacional, v. 3, n. 2, art. 2, 2010.

TROPIA, Patrícia Vieira. Minha vida, meu trabalho, nossas necessidades: condições de vida e de trabalho dos empregados no comércio de Uberlândia, 2012, mímeo.

Classe média situação de trabalho e comportamento sindical: caso dos comerciários de São Paulo. Dissertação de Mestrado, IFHC/Unicamp, Campinas, 1994. 